\title{
DO ATIVISMO PARA O EXTREMISMO JUDICIAL NAS POLÍTICAS PÚBLICAS DE ASSISTÊNCIA FARMACÊUTICA
}

\author{
OF ACTIVISM FOR JUDICIAL EXTREMISM IN PUBLIC PHARMACEUTICAL \\ ASSISTANCE POLICIES
}

\section{Débora Ferreira Carneiro}

Doutora e Mestre em Ciências da Saúde pela Universidade de Brasília; Especialista em Direito Público pela Faculdade Processus. E-mail: fcarneirodebora@gmail.com

Recebido em: 08/04/2018

Aprovado em: 11/08/2018

RESUMO: A base dos estados constitucionais está na separação dos poderes. Com a evolução dos estados modernos, a partir das teorias do neoconstitucionalismo, a separação tornou-se mais fluída, com o objetivo de dar maior efetividade aos direitos fundamentais garantidos na constituição. A partir desse momento, o Poder Judiciário abandona a inércia inicial e ganha força em decisões mais efetivas. O protagonismo judicial, chamado de ativismo judiciário, pode ser um importante mecanismo dos cidadãos para proteção dos seus direitos contra a inércia legislativa e a burocracia executiva. Contudo, os juízes quando excedem no poder decisório, podem desrespeitar a tripartição de poderes. Esse movimento de extremismo judicial é prejudicial ao Estado Democrático de Direito. É fácil perceber essas posições extremadas em relação às políticas públicas relacionadas ao direito à saúde. O Estado juiz extremista, desrespeita as políticas públicas, desrespeita o orçamento público, desrespeita os direitos da coletividade e impõem obrigações à Administração, sem a avaliação das consequências e sem que isso gere justiça social efetiva. Em relação às políticas públicas relacionadas à assistência farmacêutica, a Administração Pública acumula sucessivas derrotas judiciais, pois, praticamente todos os pedidos de fornecimento de medicamentos são concedidos. Comportamento que se tornou generalizado no país. Quem mais lucra é a indústria farmacêutica, que garante um mercado consumidor aberto, livre de questionamentos e rentável, com as decisões judiciais. É necessário um diálogo amplo entre o poder judiciário, a Administração pública, médicos, órgãos de controle e sociedade civil para que os direitos fundamentais sejam garantidos de forma eficiente e justa.

Palavras-chave: ativismo judicial.extremismo judicial.políticas públicas.direito à saúde, assistência farmacêutica.

ABSTRACT: The basis of constitutional states lies in the separation of powers. With the evolution of modern states, from the theories of neo-constitutionalism, the separation became more fluid, with the objective of giving greater effectiveness to the fundamental rights guaranteed in the constitution. From that moment, the Judiciary leaves the initial inertia and gains strength in more effective decisions. Judicial advocacy, called judicial activism, can be an important mechanism for citizens to protect their rights against legislative inertia and executive bureaucracy. However, judges when they exceed in the decision-making power, can disrespect the tripartition of powers. This movement of judicial extremism is detrimental to the Democratic State of Law. It is easy to see these extreme positions in relation to public policies related to the right to health. The State, an extremist judge, disrespects public policies, disrespects the public budget, disrespects the rights of the community and imposes obligations on the Administration, 
without evaluating the consequences and without generating effective social justice. In relation to public policies related to pharmaceutical assistance, the Public Administration accumulates successive judicial defeats, since almost all requests for the supply of medicines are granted. Behavior that has become widespread in the country. Who profits most is the pharmaceutical industry, which ensures an open consumer market, free of questioning and profitable, with judicial decisions. A broad dialogue is needed between the judiciary, the public administration, physicians, control bodies and civil society so that fundamental rights are efficiently and guaranteed

Keywords: judicial activism. judicial extremism. public policy. right to health, pharmaceutical assistance

SUMÁRIO: Introdução; 1. Constitucionalismo, Neoconstitucionalismo e judicialização da política; 2. Ativismo versus extremismo judicial; 3. A influência do ativismo ou extremismo judicial nas políticas públicas de assistência farmacêutica; Conclusão; Referências.

\section{INTRODUÇÃO}

O objetivo do presente trabalho é analisar o ativismo e o extremismo judicial nas políticas públicas, especialmente nas políticas de assistência farmacêutica, que são diuturnamente questionadas na justiça pela celeridade do avanço tecnológico. A ascensão do Judiciário sobre questões das searas legislativa e executiva, a efetividade das políticas públicas, a individualização dos direitos e a discussão de questões financeiras e orçamentárias como condicionantes de políticas públicas são alguns dos fatores relacionados a esse fenômeno e que merecem reflexão.

A teoria da separação dos poderes de Montesquieu inovou as práticas políticas por deixar claro a necessidade de equilíbrio entre os três pilares do governo: os que legislam, aqueles que executam e fazem acordos com outros Estados e, finalmente, os que julgam. E ainda ressaltou que o equilíbrio só poderia ser alcançado sem o abuso de poder, embora soubesse que todo homem que tem poder sofre a tentação de abusá-lo. (MONTESQUIEU, 2007, p, 164).

Após a Segunda Guerra Mundial, o pensamento em relação a separação dos poderes, no seu aspecto formal e funcional, foi sendo alterado, pela necessidade de efetivação dos direitos fundamentais, sejam direitos individuais, sejam direitos sociais. Houve uma ascensão do Poder Judiciário, que de neutro, passou a discutir questões políticas. A judicialização de questões relevantes do ponto de vista social e moral, projetou o próprio poder e gerou um movimento deliberado de expansão conhecido como ativismos judicial (BARROSO, 2012, p. 24-27).

A Constituição Federal de 1988 assegurou uma série de direitos e garantias. Alguns desses direitos possuem o caráter negativo, de predominância individual, de abstenção do Estado e outros, com de caráter positivo, são direitos prestacionais, executados por meio de políticas públicas. Direitos sociais não são direitos de um indivíduo, mas um direito de toda a sociedade, com a adoção de um modelo de Bem-Estar Social.

Segundo Timm (2013, p. 56-57), a caracterização desse Estado de Bem-Estar Social é descrita por dois elementos: seguros compulsórios e atividades redistributivas. Normas jurídicas são utilizadas para estimular formas obrigatórias de cooperação e solidariedade entre as comunidades, em uma tentativa de viabilizar a convivência e a paz social. A comunidade exige políticas públicas porque em um país de Bem-Estar Social são elas meios de reivindicação. Na área da saúde, por exemplo, se exige não só melhores tratamentos médicos, mas tudo o que esteja ligado, direta ou indiretamente, à saúde (ARNAUD et al, 2009, p.33).

Levando em consideração os preceitos do sistema capitalista, o Direito Social, próprio do Estado Social, quer gerar justiça, permitindo a acumulação capitalista, mas evitando alguns impactos negativos, que desestabilizariam a coesão social (TIMM, 2013, p. 57). Mas esse mesmo Estado Social possui, como característica inerente, a escassez de recursos (AMARAL e MELO, 
2013, p. 91). Daí a necessidade de políticas públicas racionais e eficientes que levem a sério as questões financeiras e orçamentárias, porque, a contrário senso, tais questões não são menores ou menos importantes que os direitos fundamentais. Cabe ao Poder Judiciário a fiscalização na eficiência dos gastos para efetivação dos direitos e garantias fundamentais, não a alteração da destinação das verbas, como se fosse "ordenador de despesas" (CARNEIRO, 2017, p. 288).

Ações que deveriam ser exceções para sanar a ineficiência dos outros poderes constituídos, pouco a pouco, foram se tornando regra e o Judiciário passou a atuar de forma mais criativa e discricionária, substituindo o legislador, muitas vezes sem a devida preocupação com os resultados de tais medidas ou com o impacto orçamentário de suas decisões (WANG et al, 2014, p. 1193). Um comportamento mais extremado, tentado pelo próprio poder, que está modificando o ativismo judicial para o extremismo judicial.

Esse extremismo judicial, em relação às políticas públicas, é mais do que uma interpretação ampliada dos direitos, mas a ampliação desmedida da discricionariedade do julgador, que não apenas julga conforme as leis, mas cria as leis, desconsidera os poderes constituídos, as questões orçamentárias e o próprio significado de direito social. Ao invés de proteger o direito, o extremismo judicial se tornou em mais uma fonte de iniquidades.

\section{CONSTITUCIONALISMO, NEOCONSTITUCIONALISMO E JUDICIALIZAÇÃO DA POLÍTICA}

O Constitucionalismo moderno, meados do século XVIII, representou um movimento político, social e cultural, que questionou nos planos político, filosófico e jurídico os esquemas tradicionais de domínio político, sugerindo uma nova ordenação e fundamentação do poder.

Não foi apenas um movimento, restrito a uma região ou Estado, mas o somatório de vários movimentos. $\mathrm{O}$ constitucionalismo inglês valorou o binômio liberdade-propriedade e a soberania do Parlamento, pois este era responsável pela criação das leis. O movimento francês trouxe para ordem jurídica os direitos individuais dos homens. Já o constitucionalismo americano foi marcado pelo povo que idealizou a limitação normativa do domínio político por meio de uma lei escrita. O resultado desses movimentos foi o surgimento de uma teoria que defendia um governo limitado indispensável à garantia dos direitos em dimensões estruturantes da organização político-social de uma comunidade.

Com a determinação das funções de cada poder, tornou-se possível regular, em tese, a influência política na Administração do Estado, vista como legítima e pertinente no plano Legislativo, moderadamente legítimo no Executivo e inexistente no Judiciário (FRIEDE, 2006, p. 470). Nas palavras de Montesquieu, o Judiciário era nulo (MONTESQUIEU, 2007, p. 169).

No princípio do Constitucionalismo, a Constituição era mais do que soma de cláusulas específicas que governam poderes, ela era responsável pela organização principiológica da doutrina de separação de poderes (MANNING, 2011, p. 1946). E era respeitado os limites estabelecidos.

Numa visão econômica, esse período correspondia a formação da economia capitalista. Esse sistema econômico necessitava de segurança jurídica com o mínimo de intervenção do estado nos direitos fundamentais economicamente relevantes (propriedade, liberdade de profissão, indústria e comércio). O Estado constitucional permitia a ascensão da política da burguesia por meio da influência parlamentar, com leis gerais e vinculativas a todos.

A concepção filosófica positivista predominava inicialmente, de forma que os fenômenos jurídicos estavam reduzidos às normas postas. Nesse viés, as constituições tendiam a ser meras cartas de intenção e os direitos seriam realizados, ou permitido o seu exercício, conforme o juízo de conveniência dos poderes políticos (MAGALHÃES, 2012, p. 2855-2856). Esse foi o comportamento até o Holocausto, quando uma nova visão surgiu em relação ao Constitucionalismo. 
A partir da II Guerra Mundial, frente as atrocidades cometidas contra milhões de seres humanos, a humanidade compreendeu o valor da dignidade humana. Houve uma mudança de paradigma na teoria jurídica, com o abandono da exclusividade do formalismo das normas positivadas e recepção de valores constitucionais (MAGALHÃES, 2012, p. 2854).

O conceito de dignidade da pessoa humana é de difícil precisão. Destarte, é possível conceber duas facetas ao conceito: empoderamento e limite (OLIVEIRA, 2011, p. 95-96). Enquanto empoderamento, reflete a capacidade individual de fazer escolhas livres e trágicas. Enquanto limite, impõe restrição à autonomia do indivíduo, respeitando a sua dignidade conforme há comprometimento com a dignidade dos outros.

A dignidade da pessoa humana é apontada pela doutrina como uma fonte primordial de todo o ordenamento jurídico. Isso significa, que é um princípio fundamental que exige o tratamento do indivíduo como a razão de ser do próprio ordenamento (DANTAS, 2015, p. 6263). E a forma de explicitar esse princípio é por meio dos direitos fundamentais (SARLET, 2015, p. 112).

Com o Neoconstitucionalismo, não se tinha apenas uma teoria de limitação do poder, mas uma ponderação entre bens e valores com a interpretação sistemática da constituição (CÔRTES, 2010, p. 547). Baseado na força vinculante das Constituições, na supremacia constitucional, na eficácia e aplicabilidade integrais dos princípios, explícitos e implícitos e na interpretação constitucional buscava impedir a discricionariedade legislativa ou executiva (NELSON e MEDEIROS, 2015, p. 148), que por muitas vezes utilizavam como moeda de troca, as regras para efetivação de um direito.

A constituição não era mais um contrato entre governantes e governados, mas um acordo celebrado pelo povo e para o povo. A consequência lógica do entendimento da Constituição como Paramount law foi a elevação do Poder Judiciário como defensor da constituição e guardião dos direitos e liberdades.

A partir da aplicação das normas constitucionais era necessário concretizar os direitos fundamentais (LIMBERGER e NOGUEIRA, 2017, p. 276). O Estado de Direito se autolimitava pela garantia dos direitos e liberdades, império das leis, divisão de poderes e legalidade da Administração, ou seja, a lei tinha premência sobre a Administração, a Justiça e à sociedade (JUÁREZ, 2010, p. 908).

O Estado de Direito se transformou em Estado Democrático de Direito, porque a democracia é o fundamento, o funcionamento e a finalidade que define o direito, ficando o juiz adstrito ao cumprimento e a efetivação da lei (FIGUEIREDO e GIBRAN, 2016, p.112). A arquitetura de uma divisão de poderes rígida, estanque, já não era mais compatível com a novo caráter ideológico.

A separação tornou-se fluida para acompanhar as transformações sociais, econômicas e políticas da sociedade. Detectando o propósito geral da Constituição e o mecanismo de check and balance entre os poderes, que permite a interferência de um poder sobre o outro desde que se respeite os mecanismos previstos na Constituição (CAVALCANTI, 2017, p. 87), mesmo que se rejeitasse detalhes procedimentais, não seria classificado como uma afronta à separação dos poderes, porque o fundamental era dar efetividade à Constituição. Desta forma, a separação tornou-se mais formal do que funcional, à medida em que se mantinha o respeito pelo equilíbrio (MANNING, 2011, p. 1950).

Do ponto de vista econômico, as ideias liberais não permitiam um avanço completo do capitalismo, haja vista a dificuldade de os cidadãos mais pobres e desprovidos de liberdades valorativas acompanhar o crescimento econômico estimulado pelas cidades e seus centros industriais. O crescimento industrial era responsável pelo agravamento dos problemas sociais. Foi necessário a intervenção do Estado. O Estado Democrático de Direito se transformou em Estado Social de Direito, pois não se preocupava em assegurar liberdades aos cidadãos, mas reconhecia direitos sociais (JUÁREZ, 2010, p. 909), garantido pelas prestações sociais estatais. 
Apesar de serem chamados de direitos sociais, tais direitos se reportam à pessoa individual, e o uso do termo "social" faz referência à justiça social (SARLET, 2015, p. 48), com distribuição e redistribuição de direitos por meio de recursos financeiros. A eficácia positiva desses direitos, está diretamente relacionada com a ideia do Estado garantidor do exercício quando o titular não pode fazê-lo por si mesmo (KOZEN, 2010, p.76).A finalidade originária dos direitos sociais é a promoção da igualdade substantiva e não uma mera igualdade formal perante a lei (MAGALHÃES, 2017, p. 2851). A mudança de postura do Judiciário era fundamental para operacionalização dessa mudança.

Entretanto, por mais que se queira tratar o Estado de bem-estar Social apenas pelos seus mecanismos de distribuição de benefícios sociais, estimulando (ou impondo) a cooperação e a solidariedade entre a comunidade, não é possível ignorar que a sociedade ainda é capitalista. Uma economia capitalista é monetizada e tudo tem um preço. Os direitos fundamentais, principalmente os direitos sociais, também possuem um preço, a ser suportado pelo recolhimento de tributos e contribuições sociais (TIMM, 2013, p. 56).

Da ascensão do Poder Judiciário e pela sua nova postura diante da resolução de conflitos, novas teorias foram surgindo para explicar esse movimento. A necessidade de preservar a integridade dos direitos fundamentais, com base em um princípio indeterminado (conceitualmente) gerou uma nova tarefa aos magistrados. Não bastava dizer que determinada ação ou omissão desrespeitava a dignidade humana, mas era necessário demonstrar o caminho percorrido pelo raciocínio, se possível com critérios relativamente objetivos, indicando valores sócio jurídicos que delineiam o ideal de justiça (GARCIA, 2008, p. 134-135).

Dentro dessas novas teorias, ainda há muita confusão na doutrina entre os termos "ativismo judicial" e "judicialização da política", sendo utilizados como sinônimo ou como atitudes opostas e valoradas, para o bem ou para o mal. Portanto, para este trabalho foi utilizado como definição de judicialização da política o conceito de Villalobos (2015, p.181), na qual supõe a limitação e a racionalização dos conflitos através do direito. É a possibilidade de levar até o Poder Judiciário os conflitos, para que ele, como fiel da balança, resolva conforme os princípios legais. O Poder Judiciário expande o processo decisório nas democracias contemporâneas por atuar em áreas reservadas, anteriormente, aos Poderes Executivo e Legislativo, com a finalidade de garantir a plena realização das normas constitucionais e a efetivação dos direitos fundamentais (CAVALCANTI, 2017, p. 92-93).

A judicialização da política, derivada da mudança axiológica do Constitucionalismo, de liberal para democrático-social, tem por base múltiplos fatores, como a centralidade da constituição e sua força normativa. Com esse protagonismo, o Poder Judiciário deslocou decisões estratégicas sobre temas fundamentais para a sua seara (LEAL, 2014, p. 129).

A partir da judicialização da política foi possível observar quatro consequências do processo: (a) aumento do impacto das decisões judiciais nos processos políticos e sociais; (b) aumento da resolução de conflitos políticos nos tribunais; (c) a construção da legitimidade do Estado sobre a base de conceitos legais (valoração do rule of law e dos direitos fundamentais); e (d) a utilização de mecanismos legais para articular, por meio de demandas judiciais, distintos interesses econômicos, políticos e sociais (VILLALOBOS, 2015, p. 177).

O Brasil não ficou alheio a esse movimento mundial, apesar do processo ser mais lento, ou discreto, dada a história política do país. A partir de 1988, com a nova Constituição Federal, a judicialização foi institucionalizada, como direito fundamental no artigo $5^{\circ}$, inciso XXXV (inafastabilidade da jurisdição), para qualquer lesão ou ameaça de lesão.

Já o ativismo judicial, é uma classe de interpretação, livre de todo vínculo textual e que favorece a criação do direito por parte dos juízes, com o propósito de adaptar às necessidades da vida real aos princípios constitucionais (VILLALOBOS, 2015, p. 180).

Apesar do assunto não ser novo, o ativismo ainda provoca inúmeras discussões, com doutrinadores pró e contra a esse comportamento, e um ponto em comum: a falta de precisão dos 
termos. O termo "ativismo" é utilizado, por vários doutrinadores, com fundamental ao Estado por ser a garantia de defesa dos direitos fundamentais e gerador de transformações sociais (ASSIS, 2012, p.293), ou pelos contrários à atitude, com um significado de arbitrariedade, que não corresponde ao significado original das ciências sociais (STRAPAZZON e GOLDSCHMIDT, 2013, p. 615). Daí a opção pelo termo “extremismo judicial”, pois também é um comportamento de enfrentamento perante uma questão política, mas um comportamento mais extremado.

\section{ATIVISMO VERSUS EXTREMISMO JUDICIAL}

Andrei Koerner (2013, p. 76-77), refletindo sobre os aspectos relacionados ao ativismo judiciário (e nesse caso, utilizando o termo tanto para o lado positivo, quanto para o lado negativo), afirmou que a análise política do pensamento jurídico, se realiza em três aspectos: a) institucional (dos arranjos de instituições); b) do pensamento jurídico (como o agregado jurídico e as relações de poder eram problematizadas); e c) a dimensão histórica (processos que geraram a formação social). Assim regime jurisprudencial formularia problemas, doutrinas e conceitos, num esquema interpretativo. Os processos judiciais representariam a oportunidade para mobilização devido a redefinição de problemas e soluções jurídicas.

Essa atuação mais inovadora do Poder Judiciário teve como marco o julgamento do caso Marbury v. Madison, nos Estados Unidos, em 1803, quando se iniciou o controle de constitucionalidade difuso (LIMBERGER e NOGUEIRA, 2017, p. 266). A partir dessa decisão, a Constituição se tornou parâmetro para as decisões nos tribunais e os juízes passaram a interpretar as leis. Na Alemanha, a atividade do Tribunal Constitucional também chegou a ser classificada como ativista, originando a corrente chamada "jurisprudência de valores" (STRECK et al, 2009, p. 77).

De acordo com Strapazzon e Goldschmidt (2013, p. 579-580), o termo ativismo judicial foi cunhada nos Estados Unidos, na Era do New Deal. O primeiro uso público do termo foi atribuído ao historiador e analista político norte-americano Arthur Meier Schlesinger Jr que o utilizou conforme a teoria sociológica, ou seja, ativismo judicial era um tipo de comportamento, uma postura de enfrentamento diante de uma questão política. Uma postura de liderança que assume o encargo de organizar e mobilizar um grupo ou toda a sociedade, na defesa de uma causa progressista ou conservadora.

A ideia está presente na literatura jurídica inglesa desde o século XIX, pois a atuação inovadora do Poder Judiciário afrontava o Poder Legislativo (STRAPAZZON e GOLDSCHMIDT, 2013, p. 578). Segundo o Ministro Luís Roberto Barroso, a ideia está associada a uma participação mais ampla e intensa do Poder Judiciário na concretização dos valores e fins constitucionais, com maior interferência no espaço de atuação dos outros poderes (BARROSO, 2012, p. 24-25).

A possibilidade de interpretar a norma ampliou a concretização dos direitos. Essa postura proativa procurou extrair o máximo as potencialidades do texto constitucional (SILVA e JUCATELLI, 2017, p. 92). Para os países que adotaram o sistema da common law, o ativismo judicial se manifestou mais facilmente, porque a cada decisão o juiz podia otimizar o direito por meio de precedentes (CÔRTES, 2010, p. 160).

Apesar de ter como ideal a concretização dos direitos, o ativismo judicial americano provou que a interpretação podia ser tanto para a expansão, quanto para a restrição dos direitos. Destaca-se os casos Dred Scott v. Stanford (1857), que corroborou a segregação racial, negando a cidadania a americanos negros e livres e afirmando que a igualdade na Constituição Americana não abrangia os afrodescendentes, e Brown v. Board of Education (1954), que declarou que a segregação racial nas escolas violava o princípio da igualdade. A postura mais ativista ou mais conservadora do juiz ou da Corte dependia do caso a ser julgado, da posição político-ideológica de seus membros e do apoio dos demais Poderes, para que as decisões judiciais tivessem 
efetividade e produzissem efeitos concretos (CAVALCANTI, 2017, p. 82-83). A evolução social, a econômica e a moral da sociedade também influenciavam nas decisões mais ou menos conservadoras, bem como na influência dos conceitos jurídicos, que se misturam e se modificam conforme o momento histórico (KOERNER, 2013, p. 79).

Países com sistema jurídico romano-germânico também evoluíram para interpretações dinâmicas dos direitos. Há margem criativa ao magistrado quando é aplicado uma "interpretação conforme a Constituição" (Verfassungskonformeauslegung), quando se ordena a correção da norma (ação comum na Corte Alemã), na interpretação e proteção de novos direitos, na explicação do conteúdo e do alcance dos princípios constitucionais, na ponderação entre direitos ou princípios conflitantes entre outras (BERNAL-CANO, 2010, p.18).

No Brasil, um bom exemplo do ativismo judicial, foi a posição adotada pelo Supremo Tribunal Federal em relação aos efeitos do mandato de injunção. A partir do julgamento dos mandatos de injunção (MI) 670, 708 e 712, relativos ao direito de greve no serviço público, o STF adotou uma posição concretista, pois não bastava declarar a omissão, era necessário viabilizar o direito violado.

Os efeitos das decisões baseadas nesse comportamento mais ativo dos juízes poderiam ficar limitados às partes processuais, ou poderiam adquirir efeitos erga omnes, para as decisões proferidas pelo STF, por exemplo. Por este prisma, o ativismo representaria a utilização do poder discricionário do juiz na decisão. Mas essa discricionariedade não é absoluta e deve apresentar contornos de juridicidade (GUIMARÃES, 2014, p. 4). A ausência de tais contornos pode representar uma arbitrariedade, um excesso na atuação do juiz que pode ser compreendido como intervencionismo (BARBOSA e SILVEIRA, 2016, p. 201).

Para diferenciar o que os doutrinadores chamam de "ativismo judicial positivo" do "ativismo judicial negativo", optou-se por um novo termo: extremismo judicial. O extremista é aquele que se posiciona no extremo de uma ideia, sem admitir possibilidades e é indiferente ao debate. Não assimila argumentos contrários ao seu, não reconhece equívocos e não está disposto a se modificar. Não precisa estar atrelado ao fanatismo ou a atos violentos, até porque a violência não está expressa apenas no seu contexto físico, mas se relaciona com comportamentos que rejeitam as regras estabelecidas, tentando criar um modelo, em que o resultado seja alcançado de forma imediata, ao invés de formas gradativas, e recusando resultados parciais.

O extremismo judicial representa o abuso do magistrado da discricionariedade na solução de conflitos. É a imposição da vontade do juiz, numa visão deturpada de construção e concretização dos direitos (LIMBERGER e NOGUEIRA, 2017, p. 280). Uma visão que transforma o magistrado no único sabedor de justiça, no salvador dos direitos constitucionais e que muda o equilíbrio entre os poderes, porque coloca o Poder Judiciário acima dos demais.

A visão extremada relativiza todo o ordenamento jurídico com base na "interpretação judicial", e transforma o Poder Judiciário em um poder constituinte permanente, substituindo os agentes políticos (FERNANDES e NELSON, 2017, p. 23-24). Há uma violação da separação dos poderes, porque os juízes anulam as decisões dos demais poderes, mesmo quando estas não contrariam a Constituição, mas contrariam a vontade do juiz, suas convicções ou valores (STRAPAZZON e GOLDSCHMIDT, 2013, p. 584-585). O debate político é ignorado pela vontade de um magistrado ou mesmo de um colegiado, não eleito.

O magistrado, durante o processo decisório, escolhe entre duas ou mais soluções possíveis, com os meios legais que lhe são oferecidos. Quando a decisão se fundamenta em uma argumentação exaustiva do porquê de tal escolha e do porquê do afastamento de outra possibilidade, o resultado reveste-se de legitimidade (LEAL e BOLESINA, 2013, p. 517). Mas o que se observa no extremismo judicial é a subversão da escolha, por não concordar com a norma legal ou com a política pública estabelecida, o juiz afasta a norma legal, sem uma análise de constitucionalidade, argumenta, de forma abstrata e superficial, sobre princípios e impõe sua vontade, a sua visão de justiça social (GUIMARÃES, 2014, p. 9). Torna-se um justiceiro. Em 
muitos casos, pela mera necessidade de responder, o juiz afasta o julgamento, a ponderação dos princípios, a consideração de omissões e a análise dos impactos da sua decisão (TEIXEIRA, 2012, p. 50) e uma decisão arbitrária, aleatória ou míope reveste-se de injustiça, para a parte lesada e para o ordenamento jurídico (LEAL e BOLESINA, 2013, p. 517).

Os princípios constitucionais não se aplicam ordinariamente como determinações de dever-ser, mas prioritariamente, quando houver a necessidade de interpretação das normas infraconstitucionais ao texto constitucional (GUIMARÃES, 2014, p.8). Segundo Barbosa e Silveira (2016, p. 19), quando o juiz extrapola na decisão, a ponto de inovar a norma, obrigando que uma parte da verba pública seja destinada para atender a demanda individual, ele unifica os três Poderes em uma única pessoa.

Com tais decisões, observa-se uma banalização das decisões judiciais, seja pelo seu descumprimento, seja pela desmobilização dos movimentos e organizações sociais (ALVAREZ, 2015, p.97). As organizações deixam de ser ambientes de mobilização e luta pela concretização ou pelo reconhecimento de novos direitos porque o Judiciário tornou-se o centro das decisões.

\section{A INFLUÊNCIA DO ATIVISMO OU EXTREMISMO JUDICIAL NAS POLÍTICAS PÚBLICAS DE ASSISTÊNCIA FARMACÊUTICA}

Saúde, educação, saneamento básico, segurança pública são alguns aspectos da vida do cidadão dependentes de políticas públicas. As políticas públicas representam os instrumentos de ação da Administração. São um conjunto de medidas praticadas pelo Estado capazes de efetivar os direitos fundamentais ou o Estado Democrático de Direito (FREIRE JÚNIOR, 2005, p. 47).

Depreende-se, então, que as políticas públicas se destinam a racionalizar a prestação coletiva do Estado, com base nas principais necessidades da população, de forma a promover justiça distributiva inerente aos direitos sociais (MARQUES, 2008, p. 66). O orçamento é o meio utilizado para operacionalizar as políticas públicas, além de definir a concretização dos valores fundamentais da constituição (MÂNICA, 2014, p. 2-3). No caso das políticas públicas relacionadas à saúde, o aspecto axiológico do direito à saúde confere uma força maior ao debate nos tribunais brasileiros.

As práticas de saúde são processos sociais que geram quadros complexos onde as necessidades emergentes dependerão do peso maior ou menor dos fatores internos (circunstâncias do ciclo do ser humano) e externos (dinâmica coletiva de reprodução da vida social) (MARSIGLIA et al., 2005, p. 71). O direito à saúde, conforme a Constituição Federal, impõe obrigações tanto de caráter originário, (como a implementação do SUS, da aplicação mínima dos recursos em saúde e do dever geral de respeito à saúde), quanto de caráter derivado (legislação infraconstitucional) (SARLET e FIGUEIREDO, 2012, p. 33).

$\mathrm{O}$ direito à saúde representa a união entre os princípios de igualdade e equidade (PINHEIRO et al, 2005, p. 15), pois seriam tais princípios a base da universalização e o foco das políticas sociais para a redução de vulnerabilidades (OCKÉ-REIS, 2012, p. 22). Restringir o direito à saúde ao acesso as novas tecnologias é menosprezar todo o arcabouço de direitos que se relacionam com o direito à saúde (CARNEIRO, 2017, p. 282).

Em relação às políticas públicas de assistência farmacêuticas, a Organização Mundial da Saúde (OMS) recomenda que, em relação à seleção de medicamentos, o rol seja estabelecido por cada país, contemplando as necessidades terapêuticas da população, além de propiciar a melhoria na qualidade da assistência (PEPE, et al., 2010, p. 462). Para a OMS, a formulação de uma política de medicamentos implica na definição de um conjunto de diretrizes com finalidade de assegurar medicamentos seguros, eficazes, de boa qualidade, incluindo a produção, distribuição, legislação, registro, prescrição, dispensação, qualidade e propaganda comercial (DALLARI, 2010, p. 65). A melhoria da assistência é resultado da limitação de medicamentos sem eficácia comprovada, que apresentam maiores riscos do que benefícios ou a duplicidade de fármacos para 
a mesma indicação clínica. O objetivo principal das políticas é garantir o acesso e o uso racional de medicamentos essenciais de alta qualidade (CHIEFFI et al, 2017, p. 499). Medicamentos essenciais são definidos como aqueles que satisfazem as necessidades prioritárias de cuidado de saúde da população (SANT'ANA et al, 2011, p. 139).

Dentre as várias regulações do Sistema Único de Saúde (SUS) e ao encontro da recomendação da OMS encontra-se a Política Nacional de Medicamentos (PNM), que tem como escopo reforçar os princípios e diretrizes do SUS, buscando garantir a eficácia e segurança no uso racional de medicamentos essenciais. Em 2004, foi aprovado a Política Nacional de Assistência Farmacêutica (PNAF) que envolve um conjunto de ações voltadas à promoção e recuperação da saúde.

O uso racional não significa racionamento de medicamentos, mas, com base na razão, busca-se promover o uso de medicamentos que tenham evidências científicas garantidoras de sua segurança e efetividade (PINTO et al, 2015, p. 37). A perspectiva adotada na seleção dos medicamentos é epidemiológica, buscando a coletividade. $\mathrm{O}$ alto custo do medicamento não o exclui da lista, porque a escolha conjuga o binômio custo-benefício (SANT'ANA et al, 2011, p. 139). Com base nesses princípios, a seleção da RENAME (Relação Nacional de Medicamentos Essenciais) atende, em média, 90\% dos casos (PINTO et al, 2015, p. 38), os outros 10\% seriam atendidos apenas em processos de judicialização da saúde, por serem medicamentos extremamente novos, por serem doenças extremamente raras, ou uma conjugação destes.

$\mathrm{Na}$ judicialização da assistência farmacêutica, Tribunais e juízes avocam o direito de influenciar no tipo de política pública a ser implementada, além de julgarem a legalidade ou eficácia das normas com as suas próprias regras, mesmo que para isso haja a integração de normas diversas afim de construir um "novo" modelo de assistência (MACHADO e DAIN, 2012, p. 1020). E o novo modelo é conceder a integralidade do pedido, independente dos custos, da necessidade real ou da legalidade do pedido, pois o direito à saúde foi alçado, pelos Tribunais, à condição de direito absoluto. Não existe princípio, nem direito absoluto, porque em dado momento, o direito absoluto de um cidadão irá colidir com o direito absoluto de outro e a consequência natural da relatividade dos direitos é a possibilidade de restrição dos bens protegidos e não do direito em si (ALEXY, 2015, p. 111 e 281).

As restrições podem ser constitucionais ou infraconstitucionais, cuja criação é autorizada por normas constitucionais (ALEXY, 2015, p. 286). Frisa-se que as restrições devem se referir a maneira de prestar ou organizar um direito, até porque as normas são formuladas em abstrato e, que, portanto, a decisão do seu conteúdo torna-se uma questão política (ALEXY et al, 2015, p. 508).

Tais conflitos, somados ao aumento do advento de novas tecnologias de saúde, geram uma maior atividade do Judiciário, seja pelo ativismo, na garantia de pleno exercício dos direitos fundamentais, seja pelo extremismo, com desrespeito às normas e políticas. Para um medicamento não padronizado (aquele que não está na RENAME), quando concedido pelo Poder Judiciário, sem nenhum critério, além do "direito à saúde", para um indivíduo ou pequeno grupo de indivíduos, não está realizando controle jurisdicional da política pública, mas tão somente atendendo o direito de ação (MORETTI e COSTA, 2016, p. 122). É a justiça promovendo o consumismo inconsequente, mas a lógica sanitária é pública e o titular do direito não é o consumidor, mas um cidadão (MACHADO e DAIN, 2012, p. 1030). A universalidade do direito não significa que toda e qualquer prestação em saúde deva ser atendida, pois há que se diferenciar o interesse particular do interesse de âmbito coletivo, de proteção à saúde (RAMOS e DINIZ, 2016, p. 46).

A intervenção do Poder Judiciário é necessária quando fica demonstrado a inércia do Poder Executivo na execução das obrigações ou na má gestão dos recursos nas políticas públicas. Há que se ressaltar que a realização de direitos está diretamente relacionada com a aplicação dos recursos e, quando se trata de um direito como o direito à saúde, que apresenta um objeto tão 
amplo, o processo decisório esbarrará na questão: qual aspecto da saúde o gestor deverá investir mais ou menos recursos?

A pressão pela incorporação de novas tecnologias em saúde, principalmente no componente farmacêutico, ocorre não só no Brasil, mas em diversos países do mundo. Apesar da relação com o direito à saúde ser distinto em cada país (em vários países não é considerado como direito fundamental. $\mathrm{O}$ Brasil só promoveu o direito à saúde para condição de direito fundamental com a Constituição de 1988), o que dificulta a comparação, as questões relacionadas à saúde são as mesmas e demandam grandes esforços dos governos na administração e na solução de conflitos. As novas tecnologias trazem benefícios, riscos e custos para a sociedade, daí a necessidade de ponderação e avaliação (GOMES, 2015, p. 147).

No Brasil, foi criado a comissão Nacional de Incorporação de Tecnologias do SUS (Conitec) com função de assessorar o Ministério da Saúde nas decisões relativas à incorporação, exclusão ou alteração de novos medicamentos, produtos e procedimentos (CAETANO et al, 2017, p. 2514). No período de 2012 a junho de 2016, foram 485 solicitações, sendo 92,2\% relacionadas a incorporação (destes, 62,1\% relacionadas a medicamentos) (CAETANO et al, 2017, p. 2516-2521).

Para as doenças raras, a judicialização é a única via de aquisição do medicamento, que pode não promover a cura, mas, em tese,melhora a qualidade de vida. São drogas muito específicas, extremamente caras, e que não são consideradas essenciais pela OMS (VARGASPELÁEZ et al., 2017, p. 170).

Talvez o custo com essas medicações específicas não gerasse tantas discussões, se o Estado não tivesse que gastar valores exorbitantes em processos judiciais para garantir medicamentos não-padronizados para doenças que já possuem cobertura farmacêutica na RENAME. O Ministério da Saúde calculou que, somados os gastos municipais, estaduais e federais, a despesa com a compra de medicamentos, por via judicial, ultrapassou os $\mathrm{R} \$ 7$ bilhões em 2016, sendo que $\mathrm{R} \$ 654,9$ milhões foram para a compra de 10 medicamentos que atendiam, à época, 1.213 pessoas (PIERRO, 2017, p.20).

Só Cidade de São Paulo teve um aumento de 1.722,65\% no número de medicamentos fornecidos, com um gasto estimado para 2014 de R\$513 milhões, valor que representava 90\% do gasto anual do SUS em diagnóstico e laboratórios no Estado de São Paulo (WANG et al, 2014, p. 1993). No Estado de Pernambuco, em 2009, 134 medicamentos que foram adquiridos por ações judiciais geraram uma despesa de $\mathrm{R} \$$ 4,5 milhões (STANFORD e CAVALCANTI, 2012, p. 794).

É comum nas decisões judiciais para o fornecimento de medicamentos um desrespeito ou desprezo pelo disposto na Lei $\mathrm{n}^{\circ}$ 8.080/90 (Lei orgânica da saúde que regulamenta o dispositivo constitucional), seja para medicamentos padronizados ou não padronizados, o que afeta a organização federativa. De acordo com Wang et al (2014, p. 1198-1201), esse desrespeito à Lei gera um acesso desigual ao SUS, desequilibra a distribuição de competências (na cidade de São Paulo, por exemplo, 55\% dos gastos com judicialização foram com gastos de responsabilidade do Estado ou da União e $45 \%$ com produtos não padronizados), gera incertezas administrativas no quantumdestinar no orçamento (além do mínimo estabelecido em lei) e impacto nas contas públicas (com cortes e realocação de verbas). No cumprimento das ações judiciais ocorre desvio de recursos de outros setores ou programas, que pode resultar em mais judicialização pelos setores prejudicados. Além disso, a medicação adquirida por via judicial não é acompanhada quanto ao custo/benefício, se é realmente eficiente no tratamento, se pode ser substituída por outro ou se a sua distribuição está infringindo alguma lei ou princípio (SAVI e SANTOS, 2013, p. 405).

Novos medicamentos são lançados com frequência e, em algumas vezes, não agregam benefícios terapêuticos, apenas possuem um valor muito superior ao do medicamento já existente. Em 2002, dos 78 fármacos aprovados pela Food and Drug Administration (FDA), apenas 17 continham novas substâncias ativas, sendo que 7 eram aprimoramentos de produtos já 
comercializados e os outros 61 eram fármacos já aprovados, com variações, sem ganho terapêutico. Tais resultados revelam que à medida que ocorre um declínio do número de novidades terapêuticas, aumenta-se o conceito de doença e das indicações terapêuticas (ROZENFELD, 2013, p. 2369). A indústria farmacêutica é a maior interessada nos processos de judicialização da assistência farmacêutica porque garante a venda de produtos que não cumpriram as exigências para entrarem nas listas oficiais (SAVI e SANTOS, 2013, p. 407-408). A indústria farmacêutica, assim como qualquer outra indústria, visa lucro, e não está relacionada com promoção de saúde (D’ESPÍNDULA, 2013, p. 445).

$\mathrm{O}$ registro de medicamentos no Brasil segue as regras da Anvisa, como apresentações de relatórios técnicos com dados minuciosos dos resultados dos ensaios clínicos, estudos de estabilidade do fármaco, registro no país de origem dentre outros (D'ESPÍNDULA, 2013, p. 440). No caso das drogas para doenças raras, a indústria farmacêutica faz pressão sobre o governo federal para que sejam incorporadas apenas com o critério da "necessidade clínica" (PAUMGARTTEN, 2016, p. 5)

$\mathrm{Na}$ Alemanha, o processo de compra passou a ser em duas fases, após a publicação do Ato de Reestruturação Farmacêutica da Alemanha (AMNOG): a) primeira fase, na qual o novo produto é avaliado para determinação de sua eficiência e do ganho terapêutico; por meio de duas agências; b) segunda fase, o preço é negociado com a indústria, e se não houver acordo, o preço é arbitrado (LAUENROTH e STARGARDT, 2017, p. 927). Por Lei, as substâncias farmacêuticas que não acrescentam benefícios em relação ao padrão, não podem custar mais que a referência. Para as formulações que apresentam ganhos terapêuticos, o aumento em relação ao tratamento padrão pode aumentar, em média, 286,4\% (LAUENROTH e STARGARDT, 2017, p. 929). O tipo de benefício, a intensidade do benefício, a área terapêutica e o efeito sobre a mortalidade são alguns fatores que determinam a variação do aumento de preço para as substâncias que apresentaram ganhos terapêuticos.

Vargas-Pelález el al (2014, p. 53), por meio de uma revisão sistemática, observaram que nos processos de judicialização da saúde, a interpretação do direito à saúde é diferente entre a Europa e a América Latina. Enquanto na Europa os juízes priorizam o social, sobre o individual, na América Latina os juízes tendem a valorizar o aspecto individual, sem considerar os impactos no sistema de saúde ou no restante da população. Países com uma cultura liberal possuem políticas de saúde de forma residual e se referem principalmente a assistência social; países com uma cultura conservadora, as políticas de saúde são baseadas em direitos e deveres com o estado ocupacional; e nos países com uma cultura socialdemocrata possuem um sistema de saúde mais intervencionista com a finalidade de corrigir inequidades (VARGAS-PELÁEZ et al, 2017, p. 172). É a chamada justiça distributiva.

Com a medicalização da saúde, a sociedade não se contenta com o uso de medicamentos consagrados em seus efeitos, mas está sempre em busca do elixir da vida eterna, a verdadeira fonte de felicidades (D’ESPINDULA, 2015, p. 445). Ignoram que a morte não é um castigo ou uma punição, mas a consequência natural da vida.

Por fim, é importante destacar que a promoção dos direitos consubstanciados no princípio da dignidade humana, como os direitos à vida e à saúde, recai também sobre os particulares, pela horizontalidade constitucional, tornando sua efetividade uma obrigação tanto do Estado quanto dos cidadãos (ARNOLD et al, 2012, p.102-103). A correta interpretação do direito à saúde exige um aprofundamento das questões relativas ao direito constitucional, administrativo e sanitário, com as questões médicas, sociais e econômicas (RAMOS e DINIZ, 2016, p. 54). 


\section{CONCLUSÃO}

O ativismo judiciário é um mecanismo importante dentro das democracias modernas. Longe de provocar desequilíbrios entre os Poderes Estatais, é uma forma segura de garantir que os direitos fundamentais sejam respeitados.

Contudo, há que se considerar, que a prática do ativismo judicial deve ser reservada quando evidenciam desrespeitos à Constituição. A partir do momento que não se verifica um desrespeito constitucional, as decisões judiciais que alteram as políticas públicas passam a ser extremadas e podem trazer consequências deletérias às Instituições.

A garantia ao direito à saúde é um assunto muito especial, pois está relacionado a vários outros direitos, além de causar impactos expressivos nas economias. A assistência farmacêutica, inclusa na universalidade e na integralidade do direito à saúde, não se refere apenas ao direito de um indivíduo, buscando na medicação um consolo, mas ao direito de uma comunidade.

Não é cabível a omissão estatal no cumprimento do mínimo existencial (no Brasil, o mínimo é na literalidade da palavra), no desrespeito as suas obrigações, no descaso com a aplicação dos recursos públicos, que oriundos dos tributos, não se revertem em benefícios à população. Nesse contexto, o ativismo judicial, a postura mais dinâmica dos magistrados, é fundamental para assegurar que todos tenham direitos.

Mas também não é possível, o desrespeito judicial às leis infraconstitucionais, sem que haja um questionamento da sua constitucionalidade. Não é cabível o desrespeito judicial ao princípio da separação dos poderes para que se cumpra sua verdade, sem a devida análise dos fatores que a compõem. Não é cabível ao judiciário o desrespeito às leis orçamentárias e ao próprio orçamento público, quando estas se amoldam a constituição, mas não garantem todos os desejos individuais. Não é cabível as decisões judiciais que obrigam os gestores públicos praticarem outras ilegalidades.

Portanto, faz-se mister o diálogo entre os gestores públicos e o Poder Judiciário e entre estes e as áreas técnicas, para que os cidadãos possam receber do Estado aquilo que lhes é devido, seja na assistência farmacêutica, seja em relação a qualquer outro direito fundamental. Que os aspectos meramente pessoais sejam postos de lado e a discussão alcance o coletivo.

\section{REFERÊNCIAS}

ALEXY, R. Teoria dos direitos fundamentais. 2 ed. São Paulo: Malheiros Editores, 2015. 669p.

ALVAREZ, L. Judicialização de la política y soberania popular: sobre el estatuto político de las resoluciones judiciales. Revista Crítica de Ciências Sociais, Coimbra, v. 108, p. 95-110, dez. 2015.

AMARAL, G.; MELO, D. Há direitos acima dos orçamentos? In: SARLET, I. W.; TIMM, L. B. (org). Direitos Fundamentais: orçamento e "reserva do possível". 2. Ed. Porto Alegre: Livraria do Advogado, 2013. 412p. p.79-100.

ARNAUD, A-J; CAPELLER, W. Cidadania e direito à saúde. In: COSTA, A. B.; SOUSA JUNIOR, J. G. de; DELDUQUE, M. C. et al (org) O Direito achado na rua: Introdução crítica ao direito à saúde. Brasília: CEAD/UnB, 2009. 406p. p. 31-47.

ARNOLD, R.; ESTOY, J. I. M.; URBINA, F. Z. El principio de proporcionalidade em la jurisprudência del Tribunal Constitucional. Estudios Constitucionales, Chile, año 10, n. 1, p. 65116, 2012. 
ASSIS, V. H. S. de O controle judicial das políticas públicas: a problemática da efetivação dos direitos fundamentais sociais. Espaço Jurídico, Joaçaba, v. 13, n. 2, p. 283-296, jul./dez. 2012.

BARBOSA, K. de S.; SILVEIRA, R. dos R. O retorno do rei: as mutações na clássica divisão de poderes pela judicialização nas relações sociais e ativismo judicial. Revista Jurídica, Gestão $e$ Administração da Justiça, Curitiba, v. 2, n. 2, p. 191 -213, jul./dez. 2016.

BARROSO, L. R. Judicialização, ativismo judicial e legitimidade democrática. [Syn]Thesis, Rio de Janeiro, v. 5, n. 1, p. 23-32, 2012.

BERNAL-CANO, N. El poder creador del juez em la combinación o mezcla de los procedimentos constitucionales. Revista Estudios Sócio-Jurídicos, Colombia, v. 12, n. 1, p. 1134, 2010.

CAETANO, R.; SILVA, R. M. da; PEDRO, E. M. et al. Incorporação de novos medicamentos pela Comissão Nacional de Incorporação de Tecnologias do SUS, 2012 a junho de 2016. Ciência \& Saúde Coletiva, Rio de Janeiro, v. 22, n. 8, p. 2513-2525, 2017.

CARNEIRO, D. F. Direito à saúde e judicialização da assistência farmacêutica. RDJ Revista de Doutrina e Jurisprudência, Brasília, v. 108, n.2, p. 278-292, jan.-jun. 2017.

CAVALCANTI, A. D. Ativismo judicial ou criação judicial do direito? O papel da corte constitucional nas omissões constitucionais - uma análise comparativa. Revista de Direito Brasileira RDB, São Paulo, SP, v. 16, n. 7, p. 79-95, jan/abr. 2017.

CHIEFFI, A. L., BARRADAS, R. de C. B., GOLBAUM, M. Legal access to medications: a threat to Brazil's public health system? BMC Health Services Research, Reino Unido, v. 17, p. 499-511, 2017.

CÔRTES, V. A. P. V. Ativismo judicial do neoconstitucionalismo ao neoprocessualismo. Revista Eletrônica de Direito Processual - REDP, Rio de Janeiro, v.6, n. 6, p. 546-571, 2010. Disponível em: <www.redp.com.br>. Acesso em 18 dez 2017.

D’ESPÍNDULA, T. C. de A. S. Judicialização da medicina no acesso a medicamentos: reflexões bioéticas. Rev. Bioét. (impr), Brasília, v. 21, n. 3, p. 438-447, 2013.

DALLARI, S. G. Controle judicial da política de assistência farmacêutica: direito, ciência e técnica. Physis Revista de Saúde Coletiva, Rio de Janeiro, v. 20, n. 1, p. 57-75, 2010.

DANTAS, P. R. de F. Direito processual constitucional. 6 ed. São Paulo: Atlas, 2015. 556p.

FERNANDES, R. L.; NELSON, R. A. R. R. Da capacidade de inovação normativa do poder judiciário: uma análise a partir do sistema jurídico brasileiro. Revista Prólegomenos Derecho y Valores, Nova Granada, v. 20, n. 39, p. 11-28, 2017.

FIGUEIREDO, E. F. de; GIBRAN, S. M. O ativismo judicial, o princípio da separação dos poderes e a ideia de democracia. Percurso, Curitiba, v. 1, n. 18, p. 104-124, 2016.

FREIRE JÚNIOR, A. B. O controle judicial de políticas São Paulo: Revista dos Tribunais, 2005. $140 \mathrm{p}$. 
FRIEDE, R. Curso de Ciência Política e Teoria Geral do Estado. 3. ed. Rio de Janeiro: Forense Universitária, 2006.

GARCIA, E. Conflito entre normas constitucionais: Esboço de uma teoria geral. Rio de Janeiro: Lumen Juris, 2008. 612p.

GOMES, L de M. A saúde como objeto de consumo: uma análise sobre as demandas e consultas públicas de incorporação de medicamentos no SUS. Cad. Ibero-Amer. Dir. Sanit, Brasília, v. 4, n. 4, out./dez., p. 145-1632015.

GUIMARÃES, I. S. Ativismo judicial e o problema metodológico da discricionariedade judicial para a formação de uma política criminal. Universitas Jus, Brasília, v. 25, n. 2, p. 1-14, 2014.

JUÁREZ, M. G. Formas del Estado de Derecho y Delimitación del Derecho al Buen Gobierno. ARBOR Ciencia, Pensamento y Cultura, Madrid, CLXXXVI, n. 745, p. 901-915, sept.-oct. 2010.

KOERNER, A. Ativismo judicial? Jurisprudência constitucional e política no STF pós-88. Novos Estudos CEBRAP, São Paulo, v. 96, p. 69-85, julho. 2013.

KOZEN, L. A justiciabilidade dos direitos sociais: considerações a respeito da eficácia jurídicosubjetiva dos direitos fundamentais. Espaço Jurídico, Joaçaba, v. 11, n. 1, p. 63-90, jan./jun. 2010.

LAUENROTH, V. D.; STARGARDT, T. Pharmaceutical pricing in Germany: how is value determined within the scope of AMNOG? Value in Health, v. 20, p. 927-935, 2017.

LEAL, M. C. H. Corte Interamericana de Direitos Humanos e jurisdição constitucional: judicialização e ativismo judicial em face da proteção dos direitos humanos e fundamentais? Revista de Investigações Constitucionais, Curitiba,v. 1, n. 3, p. 123 - 140, set./dez. 2014.

LEAL, M. C. H.; BOLESINA, I. Fundamentação, jurisdição constitucional e direitos fundamentais - um estudo de caso. Espaço Jurídico Jornal of law, Chapecó, v. 14, n. 2, p. 511532, jul./dez. 2013.

LIMBERGER, T. NOGUEIRA, A. de C. Neoconstitucionalismo: o alicerce do ativismo judicial brasileiro. Revista Direito e Liberdade - RDL - ESMARN, Rio Grande do Norte, v. 19, n. 1, p. 263-289, jan./abr. 2017.

MACHADO, F. R. de S.; DAIN, S. A audiência pública da saúde: questões para judicialização e para a gestão de saúde no Brasil. Rev. Adm. Pública, Rio de Janeiro, v. 46, n. 4, p. 1017-1036, jul./ago. 2012.

MAGALHÃES, G. G. C. V. de. A configuração pós-moderna dos direitos fundamentais sociais: uma análise da ingerência jurisdicional no âmbito de efetivação desses direitos. RIDB, Lisboa, ano 1, n. 5, p. 2849-2889, 2012. Disponível em: < http://www.idb-fdul.com/ >. Acesso em 21 out 2017.

MÂNICA, B. F. Teoria da Reserva do Possível: Direitos Fundamentais a Prestações e a Intervenção do Poder Judiciário na Implementação de Políticas Públicas. Revista Eletrônica 
sobre a Reforma do Estado (RERE), Salvador, Instituto Brasileiro de Direito Público, n.21, março, abril, maio. 2010. Disponível em: <http://www.direitodoestado.com/revista/RERE-21MARCO-2010-FERNANDO-MANICA.pdf> Acesso em: 18 abril 2014.

MANNING, J. F. Separation of powers as ordinary interpretation. Harvard Law Review, Cambridge, v. 124, p. 1939-2036, 2011.

MARQUES, S. B. Judicialização do direito à saúde. Revista de Direito Sanitário, São Paulo, v. 9, n. 2, p. 65-72, jul.-out. 2008.

MARSIGLIA, R. M. G.; SILVEIRA, C.; CARNEIRO JUNIOR, N. Políticas sociais: desilgualdade, universialidade e focalização na saúde no Brasil. Saúde e Sociedade, São Paulo, v. 14, n. 2, p. 69-76, 2005.

MONTESQUIEU. Do Espírito das Leis. São Paulo: Martin Claret, 2007.

MORETTI, D. A. A.; COSTA, Y. F. da A importância do ativismo judicial na implementação dos direitos sociais não implementados pelo poder público. R. Dir. Gar. Fund., Vitória, v. 17, n. 1, p. 111-134, jan./jul. 2016.

NELSON, R. A. R. .R; MEDEIROS, J. T. da S. de. Reflexões sobre o ativismo judicial. Revista de Direito da Uerj-RFD, Rio de Janeiro, n. 27, p. 146-171, 2015.

OCKÉ-REIS, C. O. SUS: o desafio de ser único. Rio de Janeiro: Fiocruz, 2012. 180p.

OLIVEIRA, A.A.S. de Bioética e Direitos Humanos. São Paulo: Loyola, 2011. 245p.

PAUMGARTTEN, F. J. R. Pharmaceutical lobbying in Brazil: a missing topic in the public health research agenda. Rev. Saúde Pública, São Paulo, v. 50, n. 70, p. 1-6, 2016.

PEPE, V. L. E.; VENTURA, M.; SANT'ANA, J. M. B et al Caracterização de demandas judiciais de fornecimento de medicamentos "essenciais" no Estado do Rio de Janeiro, Brasil. Cad Saúde Pública, Rio de Janeiro, v. 26, n. 3, p. 461-471, mar. 2010.

PIERRO, B. de. Demandas crescentes. Pesquisa Fapesp 252, São Paulo, p. 18-25, fevereiro, 2017.

PINHEIRO, R.; GUIZARDI, F. L.; MACHADO, F.R.S. et al. Demanda em saúde e direito à saúde: liberdade ou necessidade? Algumas considerações sobre os nexos constituintes das práticas de integralidade. In: PINHEIRO, R.; MATTOS, R. A.(org) Construção social da Demanda. Rio de Janeiro: CEPESC/UERJ:ABRASCO, 2005. 304p. p. 11-31

PINTO, L. H., SCHULTER, L. S., SIERTH, R. et al. O uso racional de medicamentos no Brasil dentro da assistência farmacêutica e suas implicações no presente. Revista Eletrônica de Farmácia, Goiás, v. XII, n. 1, p. 27-43, 2015.

RAMOS, E. M. B.; DINIZ, I. M. Direito à saúde e judicialização: um estudo sobre a eficácia do fórum nacional do Judiciário para a saúde. Revista de Política Judiciária, Gestão e Administração da Justiça, Curitiba, v. 2, n. 2, p. 43-64, jul./dez. 2016. 
ROZENFELD, S. Ensaios clínicos e indústria farmacêutica. Cad. Saúde Pública, Rio de Janeiro, v. 29, n. 12, p. 2368-2370, dez. 2013.

SANT'ANA, J. M. B.; PEPE, V. L. E.; OSÓRIO DE CASTRO, C. G. S. et al. Essencialidade e assistência farmacêutica: considerações sobre o acesso a medicamentos mediante ações judiciais no Brasil. Rev. Panam. Salud Publica, Washington, v. 29, n. 2, p. 138-144, 2011.

SARLET, I. W. A eficácia dos direitos fundamentais: uma teoria geral dos direitos fundamentais na perspectiva constitucional. 12 ed. Porto Alegre: Livraria do Advogado, 2015. 512p.

SARLET, I. W.; FIGUEIREDO, M. F. Notas sobre direito fundamental à proteção e promoção da saúde na ordem jurídico-constitucional brasileira. In: ASENSI, F. D.; PINHEIRO, R. (org) Direito Sanitário. Rio de Janeiro: Elsevier, 2012. 614 p. p. 27-69.

SAVI, L. A.; SANTOS, E. S. O papel do administrador público nas demandas judiciais no serviço de assistências farmacêutica. Cad. Ibero-Amer. Dir. Sanit., Brasília, v. 2, n. 2, p. 404-420, jul./ dez. 2013.

SILVA, J. B.; JUCATELLI, J. P. Judicialização da saúde, ativismo judicial e o consequente desequilíbrio do orçamento público. Rev. Bras. Polít.Públicas, (online), Brasília, v. 7, n. 1, p. 89105, abril 2017.

STANFORD, A.; CAVALCANTI, M. Decisões judiciais sobre acesso aos medicamentos em Pernambuco. Rev. Saúde Pública, São Paulo, v.46, n. 5, p. 791-799, 2012.

STRAPAZZON, C. L.; GOLDSCHMIDT, R. Teoria constitucional e ativismo político: problemas de teoria e de prática com direitos fundamentais sociais. Revista Facultad de Derecho y Ciencias Políticas, Bolívia,v. 43, n. 119, p. 567-624, enero-junio. 2013.

STRECK, L. L.; BARRETO, V. de P.; OLIVEIRA, R.T. de Ulisses e o canto das sereias: sobre ativismo judiciais e os perigos da inauguração de um "terceiro turno constituinte". Revista de Estudos Constitucionais, Hermenêutica e Teoria do Direito (RECHTD), São Leopoldo, v. 1, n.2, p. 75-83, jul.-dez. 2009.

TEIXEIRA, A. V. Ativismo judicial: nos limites entre racionalidade jurídica e decisão política. Revista Direito GV, São Paulo, v.8, n.1, I, p. 37-58, jan.-jun. 2012.

TIMM, L. B. Qual a maneira mais eficiente de prover direitos fundamentais: uma perspectiva de direito e economia? In: SARLET, I. W.; TIMM, L. B. (org.). Direitos Fundamentais: orçamento $e$ "reserva do possível". 2.ed. Porto Alegre: Livraria do Advogado, 2013. 412p. p.51-62.

VARGAS-PELÁEZ, C. M.; ROVER, M. R. M.; LEITE, S. N. et al. Right to health, essencial medicines, and lawsuits for access to medicines - a scoping study.Social Science \& Medicine, v. 121, p. 48-55, 2014.

VARGAS-PELÁEZ, C. M.; SOARES, L.; ROVER, M. R. M. et al. Towards a theorical model on medicines as a health need.Social Science \& Medicine, v. 178, p. 167-174, 2017. 
VILLALOBOS, M. F. El nuevo protagonism de los jueces: uma propuesta para el análisis del activism judicial. Revista de Derecho Universidad Católica del Norte, Antofagasta, año 22, n. 2, p. 173-198, 2015.

WANG, D. W. L.; VASCONCELOS, N. P. de; OLIVEIRA, V. E.; et al. Os impactos da judicialização da saúde no município de São Paulo: gasto público e organização federativa. Rev. Adm. Pública, Rio de Janeiro, v. 48, n. 5, p. 1191-1206, set./out. 2014. 